\title{
CRIAÇÃO E DESENVOLVIMENTO DE JOGOS DIGITAIS COOPERATIVOS PARA CRIANÇAS: UMA REVISÃO SISTEMÁTICA
}

\author{
CREACIÓN Y DESARROLLO DE JUEGOS DIGITALES COOPERATIVOS PARA \\ NIÑOS: UNA REVISIÓN SISTEMÁTICA
}

\section{CREATION AND DEVELOPMENT OF COOPERATIVE DIGITAL GAMES FOR CHILDREN: A SYSTEMATIC REVIEW}

\author{
Françoise DANIELLI ${ }^{1}$ \\ Kamyla Thais Dias de FREITAS ${ }^{2}$ \\ Rubiane Guarino PEREIRA ${ }^{3}$ \\ Fernando Luiz CARDOSO ${ }^{4}$
}

RESUMO: O objetivo foi identificar estudos que criaram e testaram programas de intervenções com jogos digitais, para crianças de 7 a 10 anos, que priorizassem a cooperação. Trata-se de uma revisão sistemática, com busca realizada em sete bases de dados, utilizandose de quatro grupos de descritores (jogos digitais, programas de intervenção, população preterida e cooperação). Dois estudos foram selecionados para análise. O primeiro estudo é um jogo de realidade mista para aprendizagem de hábitos saudáveis a partir de estratégias cooperativas. O segundo é um jogo de tela para avaliar o nível de cooperação a partir de tarefas pré-estabelecidas. Os estudos produziram evidências para se acreditar na possibilidade de construção de jogos digitais que enfatizem a cooperação a fim de resolver problemas de relacionamentos sociais entre as crianças na atualidade.

PALAVRAS-CHAVE: Jogos digitais. Jogos educativos. Cooperação. Educação.

RESUMEN: El objetivo era identificar estudios que crearan y probaran programas de intervención para juegos digitales para niños de 7 a 10 años que priorizaran la cooperación. Es una revisión sistemática, con búsqueda realizada en siete bases de datos, usando cuatro grupos de descriptores (juegos digitales, programas de intervención, población diferida y cooperación). Se seleccionaron dos estudios para el análisis. El primer estudio es un juego de

\footnotetext{
${ }^{1}$ Universidade do Estado de Santa Catarina (UDESC), Florianópolis - SC - Brasil. Supervisora pedagógica no Instituto Guga Kuerten. Discente no Programa de Pós-graduação em Educação. Integrante do Laboratório de Gênero, Educação, Sexualidade e Corporeidade (LAGESC). ORCID: http://orcid.org/0000-0002-0823-3015. Email: francoiseudesc@hotmail.com

${ }^{2}$ Universidade do Estado de Santa Catarina (UDESC), Florianópolis - SC - Brasil. Doutoranda no Programa de Pós-Graduação em Educação. Integrante do Laboratório de Gênero, Educação, Sexualidade e Corporeidade (LAGESC). ORCID: http://orcid.org/0000-0002-0770-7952. E-mail: kamyla.freitas@ outlook.com

${ }^{3}$ Universidade do Estado de Santa Catarina (UDESC), Florianópolis - SC - Brasil. Discente no Programa de Pós-graduação em Ciência do Movimento Humano. ORCID: http://orcid.org/0000-0003-1867-4284. E-mail: rubianeguarino@gmail.com

${ }^{4}$ Universidade do Estado de Santa Catarina (UDESC), Florianópolis - SC - Brasil. Professor Titular junto ao Programa de Pós-Graduação em Ciência do Movimento Humano e do Programa de Pós-Graduação em Educação. Coordenador do Laboratório de Gênero, Educação, Sexualidade e Corporeidade (LAGESC). Doutorado em Sexualidade Humana - Institute for Advanced Study in Human Sexuality. ORCID: http://orcid.org/0000-0002-3074-0988.E-mail: fernando.ph.d.lagesc@gmail.com
} 
realidad mixta para aprender hábitos saludables a partir de estrategias cooperativas. El segundo es un juego de pantalla para evaluar el nivel de cooperación de las tareas preestablecidas. Los estudios han producido evidencia para creer en la posibilidad de construir juegos digitales que enfaticen la cooperación para resolver problemas de relaciones sociales entre los niños de hoy.

PALABRAS CLAVE: Juegos digitales. Juegos educativos. Cooperación. Educación.

ABSTRACT: The objective was to identify studies that created and tested intervention programs for digital games for children from 7 to 10 years old that prioritized cooperation. This is a systematic review, with search in seven databases, using four groups of descriptors (digital games, intervention programs, intended population and cooperation). Two studies were selected for analysis. The first study is a mixed reality game for learning healthy habits from cooperative strategies. The second is a screen game to assess the level of cooperation from pre-established tasks. Studies have produced evidence to believe in the possibility of building digital games that emphasize cooperation in order to solve problems of social relationships among children today.

KEYWORDS: Digital games. Educational games. Cooperation. Education.

\section{Introdução}

No âmbito da educação as novas tecnologias de comunicação e informação vêm estabelecendo desafios que exigem dos espaços educativos um reinventar-se para responder a questionamentos e demandas que colocam em dúvidas se o modelo em vigência prepara os educandos para resolver demandas no âmbito social deste tempo. Assim, pensar estratégias que promovam um interesse para a aprendizagem é o grande desafio. Nesse sentido, os jogos e as brincadeiras sempre foram grandes aliados nos processos de ensino e aprendizagem pelo seu potencial de significado e de desenvolvimento de competências e habilidades. Além de proporcionar vivências e trocas que oportunizam aprendizados, bem como a possibilidade de desenvolver aspectos físicos, motores, cognitivos, emocionais e sociais.

Nas últimas décadas, o surgimento dos jogos digitais e smartphones têm direcionado o interesse e atenção das crianças para esse tipo de mídia, desencadeando comportamentos que contemplam muitas horas dedicadas a vivenciar essa atividade. Contudo, sabe-se da importância do jogo, pois trata-se de um elemento que antecede a cultura, fazendo parte das diversas atividades desenvolvidas pelo homem durante a sua história (HUIZINGA, 1993).

Nesse contexto, os jogos podem se apresentar de várias formas, dentre as mais tradicionais estão: jogos esportivos, jogos de tabuleiro, jogos de faz de conta, entre outros. Independentemente de sua forma, os jogos são importantes para o desenvolvimento das 
pessoas, principalmente na infância, em que acontece a principal fase do desenvolvimento humano. Conforme Piaget (1971), os jogos estão conectados de forma direta ao desenvolvimento cognitivo (mental) das crianças por meio da constituição da assimilação do real quando jogam, assim tanto a aprendizagem quanto as atividades lúdicas são fundamentais para esse processo.

Esses aspectos evidenciam a importância que os jogos têm no desenvolvimento psicomotor e no processo de aprendizado na infância, além de ser fundamental no domínio social da criança. Por meio dos jogos as crianças têm a possibilidade de desenvolver os processos mentais, desenvolver a linguagem e hábitos sociais (SERAPIÃO, 2004). Por isso o jogo é essencial aos aspectos sensório-motor e do simbolismo, pois trata-se de uma assimilação do real à atividade própria, fornecendo a esta seu alimento necessário e transformando o real em função de suas necessidades múltiplas do eu (PIAGET apud SERAPIÃO, 2004).

Nesse sentido, o jogo se transforma com o passar do tempo, e no início dos anos 2000, os serious games (jogos sérios) começam a ganhar espaço como parte de uma abordagem educacional baseada em jogos digitais, que tem como característica central a união de aspectos lúdicos e conteúdos específicos. Apesar de a ludicidade ser um dos grandes diferenciais do uso de jogos digitais com fins pedagógicos, Brincher e Silva (2012) defendem que esta não é a única, nem mesmo a principal, potencialidade dos mesmos, "um primeiro passo necessário para a compreensão do uso de jogos eletrônicos como instrumento de aprendizado é aceitar sua função como uma prática significativa, como elemento formador e constituído por significados" (BRINCHER; SILVA, 2012, p. 45). Para os autores, a opção pelo uso destas ferramentas deve estar baseada em seu alinhamento com objetivos claros da proposta curricular da escola ou da turma, pois a intenção não é "transformar conteúdo em joguinho com a desculpa de tornar aquele mais atraente, mas considerar que essa passagem do meramente textual, por exemplo, ao lúdico implica muito mais que uma mera mudança de suporte" (BRINCHER; SILVA, 2012, p. 52).

Por conseguinte, há outros fatores a serem considerados no jogo, como o quanto ele fortalece a ideia de competição e cooperação. Diante de uma demanda social em que a competição é potencializada em muitas esferas sociais (ser o melhor aluno, melhor profissional, atingir as metas, etc.), oportunizar interações e aprendizados a respeito da cooperação pode fortalecer valores que contemplem aspectos do coletivo, que valorizem e acolham as diversidades e que fortaleçam uma convivência social amistosa e afetiva. Entretanto é comprovado que tanto a cooperação como a competição são elementos que são 
diametralmente opostos, mas que caminham lado a lado, sendo fundamentais para o desenvolvimento humano e o convívio social (BROTTO, 1999).

Igualmente, a competição é muito importante no contexto do jogo, conforme Huizinga (1993, p. 59): “quem diz competição, diz jogo". Dessa forma, considera-se que a competição por si só não pode ser denominada como negativa ou positiva, pois o que determina esses fatores é a forma como mediamos a atividade. Por isso a importância da mediação, principalmente na infância.

Investigações como a de Brotto (1999, p. 51) evidenciam que

estudos têm colaborado para desmistificar a Competição e Cooperação, sendo que estes estudos são fundamentais para o desenvolvimento das relações humanas em todas as dimensões e contextos. A competição e a cooperação são muito importantes com base para alicerçar de forma permanente no cotidiano das relações coletivas das pessoas seja no âmbito da vida pessoal, ou aquela vivenciada pelos grupos comunitários, pois a mesma faz parte dos comportamentos ética consciente ou inconscientemente, presente ao longo da história da humanidade" (BROTTO, 1999).

Assim, os jogos com seu potencial de aprendizagem na infância, especialmente os digitais pelo grande encantamento às novas gerações, podem ser grandes aliados no processo de ensino e aprendizagem. Contudo, os aspectos competitivos muitas vezes superam os cooperativos, premiando os mais fortes e mais ágeis, sendo esta conduta inadequada no que tange ao desenvolvimento de crianças e adolescentes, desencadeando ou estimulando dificuldade e problemas, como o bullying, a exclusão e a intolerância. E a partir desse cenário, observam-se poucos estudos que envolvam a construção de jogos digitais que contemplem a cooperação. Dessa forma, a fim de contribuir com essa lacuna, o presente estudo tem o objetivo de fazer uma revisão sistemática nas bases de dados importantes em ciências humanas e da saúde, buscando identificar estudos que criaram e testaram programas de intervenções com jogos digitais, para crianças de 7 a 10 anos, que priorizassem a cooperação.

\section{Método}

O estudo se caracteriza por ser do tipo exploratório documental, pois os documentos estudados foram selecionados por meio de um método sistemático, com o objetivo de explicitar os principais achados de pesquisas sobre o tema em questão, com um olhar qualitativo sobre a análise do material. Assim, buscamos responder quais estudos criaram e/ou testaram programas de intervenção com jogos digitais, para crianças de 7 a 10 anos, priorizando a cooperação. 
A busca foi realizada em sete bases de dados importantes em ciências humanas e da saúde, sendo elas: ERIC (Educational Resources Information Center), Web of Science, Pubmed, PsycoInfo, Scopus, Lilacs e Scielo. Os descritores utilizados foram organizados em quatro blocos: a) games, digital games, serious games, educational games; b) protocol, intervention, program; c) children, childhood, kid, child; d) cooperation, cooperative games, cooperate game, group work. Os descritores e blocos foram conectados pelos operadores booleanos $O R$ e $A N D$, respectivamente. As buscas ocorreram no mês novembro de 2018 .

Os critérios de inclusão utilizados foram: a) programas de intervenção de jogos digitais criados e testados para desenvolver a cooperação; b) trabalhos publicados no período de 2013 a 2018; c) nos idiomas inglês, português, espanhol. Por conseguinte, os critérios de exclusão foram: a) estudos que abordam transtornos, síndromes, distúrbios, lesões, trauma; b) crianças de 0 a 6 anos, adolescentes ou adultos; c) pré-escolares; d) animais e) artigos de revisão, observacionais, caso controle, transversais, descritivos; f) artigos e resumos indisponíveis.

Esta revisão sistemática foi conduzida por dois avaliadores independentes, visto que durante as etapas de análise os resultados eram confrontados, e se houvesse divergências, os pesquisadores recorriam a um terceiro avaliador. Dessa forma, inicialmente, realizou-se a exibição de títulos relacionados ao tema e os estudos foram selecionados em quatro etapas (GALVÃO et al., 2015):

a) Identificação - os estudos foram selecionados pela leitura dos títulos, tendo como base os critérios de inclusão e exclusão previamente estabelecidos;

b) Triagem - remoção dos artigos duplicados, e após a leitura detalhada dos resumos, excluíram-se os artigos cujos resumos não apresentavam relação com as palavraschave;

c) Elegibilidade - avaliação pela leitura na íntegra dos estudos restantes e a exclusão dos artigos que não abrangeram os critérios de elegibilidade supracitados;

d) Incluídos - apresentação dos artigos incluídos para revisão sistemática.

$\mathrm{Na}$ avaliação de qualidade dos trabalhos, foi utilizada a lista de verificação para estudos quase experimental JBI (Joanna Briggs Instituto Clinical avaliação para uso em Revisões Sistemáticas) (JOANA, 2017). 


\section{Resultados}

Os resultados do processo da busca dos estudos são apresentados no fluxograma dos artigos (Figura 1).

Figura 1 - Fluxograma dos artigos selecionados conforme a estratégia PRISMA

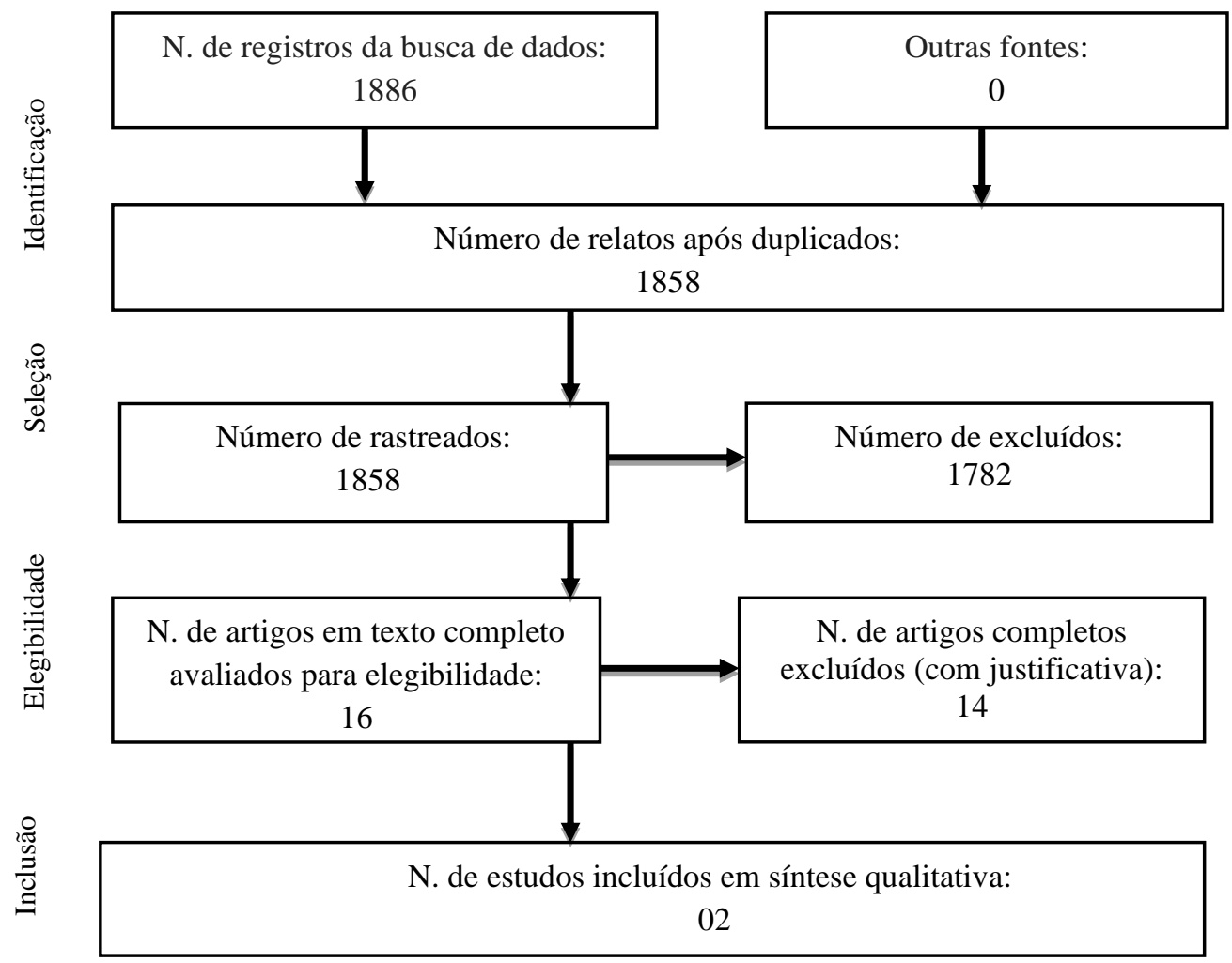

Fonte: Elaborada pelos autores (2019).

Dentre os estudos analisados somente 2 foram incluídos para a análise descritiva e crítica (Tabela 1). Ressalta-se que os estudos são recentes, sendo o mais antigo de 2013. Além disso, um estudo é da área da saúde e o outro das ciências humanas.

Tabela 1 - Lista dos periódicos selecionados a partir da Revisão Sistemática seguindo os critérios de inclusão, bem como o título, a fonte e autores

\begin{tabular}{c|c|c}
\hline Autor / Ano & Título & Periódico - Indexador \\
\hline $\begin{array}{c}\text { Johnson-Glenberg } \\
\text { e Hekler, 2013 }\end{array}$ & $\begin{array}{c}\text { "Alien Health Game" } \\
\text { an embodied exergame to instruct in nutrition and } \\
\text { my plate }\end{array}$ & $\begin{array}{c}\text { Games for Health } \\
\text { Journal - Psycoinfo }\end{array}$ \\
\hline Keil et al., 2017 & $\begin{array}{c}\text { Pizzagame: a virtual game of public goods to } \\
\text { evaluate cooperative behavior in children and } \\
\text { adolescents }\end{array}$ & $\begin{array}{c}\text { Behavior Research } \\
\text { Methods - Web of } \\
\text { Science }\end{array}$ \\
\hline
\end{tabular}

Fonte: Elaborada pelos autores (2019). 
Os objetivos dos estudos são descritos na Tabela 2. Observa-se que as investigações possuem objetivos semelhantes ao proporem a avaliação do jogo com o público-alvo. Entretanto, um jogo tem foco na aprendizagem de hábitos alimentares saudáveis, enquanto o segundo tem objetivo de mesurar o nível de cooperação com base num jogo de bens públicos.

Tabela 2 - Lista dos principais objetivos dos periódicos selecionados a partir da Revisão Sistemática

\begin{tabular}{c|l}
\hline Autor & \multicolumn{1}{|c}{ Objetivo } \\
\hline $\begin{array}{c}\text { Johnson-Glenberg } \\
\text { e Hekler, 2013 }\end{array}$ & $\begin{array}{l}\text { - Descrever o processo de desenho e desenvolvimento de minijogos } \\
\text { educacionais. } \\
\text { - Explorar a experiência de crianças ao jogar os jogos. }\end{array}$ \\
\hline Keil et al., 2017 & $\begin{array}{l}\text { - Introduzir e mostrar a viabilidade e confiabilidade de um jogo de computador } \\
\text { com características estruturais de um jogo de bens públicos, para avaliar a } \\
\text { cooperação e deserção entre crianças e adolescentes. }\end{array}$
\end{tabular}

Fonte: Elaborada pelos autores (2019).

$\mathrm{Na}$ Tabela 3 encontram-se informações sobre o desenho e métodos dos artigos analisados. O primeiro estudo trata-se de um quase experimental, na qual foram realizados pré-teste e pós-teste, bem como uma vivência com o jogo; enquanto o segundo estudo descreve os procedimentos de criação do jogo e as tarefas realizadas durante um teste, em que foi avaliado o nível de cooperação dos participantes.

Tabela 3 - Informações sobre o desenho e os métodos utilizados nos estudos selecionados

\begin{tabular}{|c|c|c|}
\hline Autor & Amostra & Procedimento \\
\hline $\begin{array}{l}\text { Johnson- } \\
\text { Glenberg e } \\
\text { Hekler, } \\
2013\end{array}$ & $\begin{array}{c}19 \text { alunos } \\
4^{\mathrm{a}} \text { série } \\
10 \text { meninas } \\
9 \text { meninos }\end{array}$ & $\begin{array}{l}\text { Inicialmente foram aplicados pré-testes, para que em outro dia os } \\
\text { alunos, em duplas, jogassem. Em seguida, os alunos eram conduzidos } \\
\text { para outra sala para completar o pós-teste (aproximadamente } 10 \\
\text { minutos). Posteriormente, os alunos voltaram para a área de jogo } \\
\text { principal para observar seus colegas jogando durante } 45 \text { minutos. }\end{array}$ \\
\hline $\begin{array}{l}\text { Keil et al., } \\
2017\end{array}$ & $\begin{array}{l}216 \text { crianças } \\
\text { e } \\
\text { adolescentes } \\
9 \text { aos } 16 \\
\text { anos }\end{array}$ & $\begin{array}{l}\text { No procedimento de desenvolvimento do jogo foram implementas } \\
\text { características estruturais de um jogo de bens públicos, considerando } \\
\text { um cenário próximo de uma situação de vida. } \\
\text { No processo de teste, os participantes foram convidados para um } \\
\text { encontro que durou cerca de } 3 \mathrm{~h} \text {. Eles receberam uma bateria de } \\
\text { medidas (por exemplo, uma tarefa de contar histórias, teste de } \\
\text { habilidades verbais, e vários questionários e entrevistas). O Pizzagame } \\
\text { foi o procedimento penúltimo do encontro. Antes de iniciar o jogo, os } \\
\text { participantes receberam informações completas sobre as regras e de } \\
\text { configuração do jogo através de uma apresentação de slides. }\end{array}$ \\
\hline
\end{tabular}

Fonte: Elaborada pelos autores (2019).

Os principais resultados dos artigos estão descritos na Tabela 4. Os dois estudos apresentaram resultados positivos em relação a desafiar e interessar os participantes. Além 
disso, a primeira investigação demonstrou resultados positivos nos critérios de aprendizagem e mudanças de comportamentos saudáveis. Por outro lado, o segundo estudo demonstrou exitosa apresentação quanto à possibilidade de avaliar os participantes individualmente, agindo coletivamente pelo bem comum.

Tabela 4 - Informações sobre os principais resultados dos periódicos selecionados a partir da Revisão Sistemática

\begin{tabular}{|c|c|}
\hline Autor & Resultados \\
\hline $\begin{array}{l}\text { Johnson- } \\
\text { Glenberg e } \\
\text { Hekler, } \\
2013\end{array}$ & $\begin{array}{l}\text { As crianças revelaram que gostaram dos minijogos e consideraram razoavelmente } \\
\text { desafiador. } \\
\text { O processo de teste piloto revelou que quase todos os participantes concluíram a maior } \\
\text { parte dos minijogos em um período razoável, sugerindo viabilidade desta abordagem. } \\
\text { O estudo sugeriu que pesquisas futuras devem continuar a explorar o uso de jogos de } \\
\text { vídeo para atingir mudanças de comportamento saudáveis em crianças. }\end{array}$ \\
\hline $\begin{array}{c}\text { Keil et al., } \\
2017\end{array}$ & $\begin{array}{l}\text { O jogo se apresentou altamente atraente para as crianças e os adolescentes. } \\
\text { Em comparação com os jogos sociais, com vários temas da vida real que requerem } \\
\text { uma coordenação, a Pizzagame simplifica muito a coleta de dados e medição de } \\
\text { estratégias cooperativas individuais. Permite a manipulação flexível das estratégias de } \\
\text { co-jogadores de várias maneiras, permitindo assim que a investigação das diferenças } \\
\text { individuais na cooperação em diferentes contextos. }\end{array}$ \\
\hline
\end{tabular}

Fonte: Elaborada pelos autores (2019).

Na Tabela 5 observa-se a avaliação da qualidade dos estudos. As investigações alcançaram 66\% de qualidade na avaliação, visto que atingiram 6 dos 9 critérios avaliados. Dentre os critérios disponíveis, dois não se aplicavam aos estudos, pois tinham relação direta com a utilização de grupos controles.

Tabela 5 - Informações sobre a pontuação na avaliação de qualidade dos estudos a partir da escala JBI

\begin{tabular}{cccc}
\hline Autor & Ano & Pontuação JBI & Porcentagem \\
\hline Johnson-Glenberg e Hekler, 2013 & 2013 & 6 & $66,6 \%$ \\
Keil et al., 2017 & 2017 & 6 & $66,6 \%$ \\
\hline
\end{tabular}

Fonte: Elaborada pelos autores (2019).

\section{Discussão}

O objetivo desse estudo foi identificar estudos que criaram e testaram programas de intervenções com jogos digitais, para crianças de 7 a 10 anos, que priorizassem a cooperação. Considerando o número de artigos encontrados após aplicação dos critérios de inclusão, entende-se que as produções científicas abordando esta temática são consideradas atuais no 
cenário acadêmico em função do recente crescimento e popularização destas tecnologias, especialmente dos jogos digitais, e sua implementação como uma ferramenta educativa.

$\mathrm{Na}$ avaliação de qualidade dos trabalhos, foi utilizado a lista de verificação para estudos quase experimental JBI (Joanna Briggs Instituto Clinical avaliação para uso em Revisões Sistemáticas), que após sua aplicação apresentou pontuação maior que 6, que representa $66,6 \%$ na escala de qualidade, e que valoriza a credibilidade das evidências produzidas nos estudos analisados.

Além da escala JBI, buscamos avaliar nos estudos outros aspectos, como o foco das propostas de aprendizagem dos programas de intervenção, constatando que os artigos selecionados tinham como objetivo potencializar a aprendizagem de conteúdo ou competências. O estudo 1 apresenta em seu programa de intervenção a proposta de aprendizagem de conteúdo por meio de escolhas alimentares saudáveis, visto que eram alimentos e conceitos que eles não tinham acesso anteriormente. Além disso, a proposta contemplava uma prática cooperativa, por meio de discussão e atividades em lousa, enquanto os participantes, organizados em duplas, interagiam com o sistema com uma tecnologia de rastreamento, apresentando os resultados da experiência de alimentarem de forma mais saudável o personagem protagonista do jogo (JOHNSON-GLENBERG; HEKLER, 2013).

Por conseguinte, no estudo 2, o objetivo dos pesquisadores foi fazer com que os participantes acreditassem que estavam jogando o jogo, na internet, com três duplas da mesma idade e do mesmo sexo (coplayers). Contudo, os coplayers foram gerados por computador e programados para expor as crianças a três condições consecutivas: (1) uma estratégia cooperativa, (2) uma estratégia egoísta, e (3) cooperação divergente - estratégias egoístas. (KEIL et. al., 2017).

Neste sentido, destaca-se o potencial dos jogos enfatizados pelo ato de brincar, ao mesmo tempo em que se proporciona a interação, a aprendizagem de regras sociais e o prazer que o ato de jogar pode proporcionar. Assim, os jogos assumem o papel de elementos mediadores entre o conhecimento já constituído, internalizado, que Vygotsky (1994) chama de nível de desenvolvimento real, e nas possibilidades e potencialidades existentes na Zona de Desenvolvimento Proximal (ZDP), que seria uma faixa intermediária para o aprendizado.

Sobre a viabilidade e confiabilidade dos estudos podemos observar que estes revelam os procedimentos metodológicos como comprovação dos impactos dos seus programas de intervenção, apresentando a sua influência no processo de aprendizagem, cognitiva ou comportamental, além de evidenciarem a necessidade de ajustes nos programas. Em relação às análises de dados, o estudo 1 (JOHNSON-GLENBERG; HEKLER, 2013) apresenta média 
e desvio padrão para avaliar o desempenho dos participantes, enquanto o estudo 2 (KEIL et. al., 2017) utiliza-se de análises como: a avaliação da consistência interna por meio do alfa de Cronbach e testa hipóteses por meio da modelagem de equações estruturais.

Nesse sentido podemos observar que os estudos citados eram todos de natureza empírica e evidenciaram a inferência em termos teóricos e/ou conceituais sobre a finalidade ou fundamentos dos jogos. Popper (1974) em seus escritos, afirma que, ao testarmos a eficácia de um recurso, partindo de procedimentos rigorosos, potencializamos a sua reprodução e a confiabilidade dos resultados obtidos. $\mathrm{O}$ fato de todas as ciências serem passíveis de teste viabiliza o critério para ser avaliada a cientificidade de uma teoria, pois temos por base procedimentos críticos, além da garantia de que na medida em que se estabelecem hipóteses, elas podem ser aceitas ou refutadas com base na experiência.

Sobre a criação e desenvolvimento dos programas de intervenção, observamos que o estudo 1 (JOHNSON-GLENBERG; HEKLER, 2013) buscou desenvolver um programa de intervenção baseado na faixa etária. Contudo, não fica evidente no estudo como foi desenvolvido, ou seja, que bases teóricas utilizaram, entretanto evidenciam que o programa valoriza a cognição incorporada para a aprendizagem. Para colocar em prática o jogo, os pesquisadores desenvolveram uma pesquisa formativa substancial, por meio de discussões em grupo, entrevistas intensivas e observações com o grupo alvo sobre a história, personagens e a representação visual, além de testes relacionados a diversão e funcionalidade dos componentes interativos. Outra especificidade do jogo é ele ter sido criado para uma plataforma de "realidade mista", ou seja, o jogo usa componentes digitais (gráficos projetados no chão), e componentes físicos (crianças manipulam varinhas de captura de movimento impresso tridimensionais para mover objetos digitais). Por conseguinte, o estudo 2 (KEIL et. al., 2017) foi criado baseado na ideia dos jogos de bem público (PGG), explicado no artigo como recursos disponíveis para serem consumidos por todos os membros do grupo, independentemente de quanto um indivíduo contribui para a sua prestação.

Nesse contexto, programas de intervenção são importantes aliados nos processos de ensino e aprendizagem; conforme Souza e Petty (2017), intervenções com jogos supõem um tipo de atuação em que o profissional consegue instigar as crianças a perceberem o que se passa com elas e almejarem produzir mudanças no que é considerado insuficiente para continuarem progredindo do ponto de vista do desenvolvimento e da aprendizagem. Entretanto, para isto acontecer, é necessário a utilização de protocolos que registram procedimentos manifestados em diferentes momentos do jogar, bem como registros de atitudes e informações fornecidas pelas famílias e professores do público-alvo. Tais dados 
resultarão na construção de um quadro da amplitude do programa de intervenção (SOUZA; PETTY, 2017).

Por fim, analisamos como cada programa de intervenção abordou a cooperação no jogo. Entendermos que os jogos cooperativos auxiliam no processo de ensino e aprendizagem, pois destacam as relações inclusivas e o trabalho com os pares. Brotto (1999) apresenta em seus escritos que os jogos que incluem a cooperação têm alto potencial de desenvolvimento de aspectos importantes das pessoas como a autoestima, o respeito, a empatia. Assim, os estudos analisados neste artigo incluem em seus programas de intervenção estratégias diferentes, mas ambas com a intenção de potencializar a cooperação. No estudo 1 (JOHNSON-GLENBERG; HEKLER, 2013), os pesquisadores contemplam a cooperação quando oportunizam uma discussão entre os participantes que estão fora do jogo, possibilitando que estes interajam e decidam juntos com os outros sobre qual alimento é o mais adequado para o personagem.

No estudo 2 (KEIL et. al., 2017), o programa de intervenção contempla diretamente a cooperação e o principal objetivo do estudo foi mostrar a viabilidade e confiabilidade do jogo, controlando para o fator de interdependência para avaliar a cooperação e deserção entre crianças e adolescentes. Eles realizaram da seguinte forma: os participantes receberam um número de fatias de pizza iguais, mas foram colocados em situação do jogo acreditando que estavam jogando on-line, com outros jogadores, entretanto esses eram gerados pelo computador (eram fictícios). As duplas eram expostas a três situações diferentes, no primeiro momento jogando com a dupla fictícia que cooperava no segundo momento com uma dupla que tinham atitudes egoístas e por fim com uma dupla fictícia que diverge em sua decisão e divide a decisão do resultado. Assim, a avaliação da cooperação acontecia nos diversos contextos propostos.

Conforme Brotto (1999) a cooperação é necessária para fundamentar permanentemente o processo de integração entre as pessoas em seu cotidiano na vida pessoal, comunitária e planetária, reconhecendo-a como uma conduta ética impreterível, que esteve, consciente ou inconscientemente, presente ao longo da nossa história. Os seres humanos não são apenas animais políticos, mas, animais cooperativos, pois, tanto os viveres políticos como o cooperativo implicam em consenso, mas o fazem de maneira diferente. Nesse sentido, a coexistência política restringe a atenção ao viver sob o domínio da luta pela dominação e submissão, e a possibilidade que oferece para a expansão da inteligência se restringe a esse domínio. A coexistência cooperativa, ao contrário, expande a atenção para o viver em todos 
os domínios possíveis de coexistência e para a aceitação da legitimidade do outro. (MATURANA apud BROTTO, 1999).

Segundo Brotto (1999), os jogos cooperativos facilitam o desenvolvimento de que dois aspectos fundamentais para as pessoas: a autoestima, que instiga e desenvolve talentos pessoais, transformando cada um em peças singulares essenciais e fundamentais ao jogo, e o relacionamento com o próximo, como um início indispensável para a aproximação de cada uma das diferentes peças para a "reestruturação" do todo. Por isso, entende-se que a cooperação é o centro no comportamento humano, pois perpassa pela característica de vida cotidiana que evidencia a confiança e o respeito mútuo. Assim, faz-se importante propor atividades de cunho coletivo cooperativo em espaços educativos, sendo que o profissional da educação será um mediador da relação dos alunos e destes com o objeto de conhecimento, proporcionando aos alunos autonomia no processo (MATSUMOTO; CAMPOS, 2008).

\section{Considerações finais}

Essa investigação teve como objetivo identificar estudos que criaram e testaram programas de intervenções com jogos digitais, para crianças de 7 a 10 anos, que priorizassem a cooperação. Dessa forma, durante a busca dos estudos, foram encontrados muitos jogos digitais com objetivos que valorizassem os processos de ensino e aprendizagem de conteúdos específicos ou com o foco no desenvolvimento de competências e habilidades, especialmente para pessoas com transtornos e deficiências, entretanto foram encontrados apenas dois estudos que contemplassem e enfatizassem a cooperação, critério de inclusão neste estudo.

O primeiro estudo tratava de um jogo de realidade mista, com objetivo de aprendizagem de hábitos alimentares saudáveis, priorizando o desenvolvimento da aprendizagem desse tema a partir de estratégias cooperativas. Por outro lado, o segundo estudo abordava um jogo de tela, que teve como objetivo avaliar o nível de cooperação dos participantes a partir de algumas tarefas pré-estabelecidas realizadas no computador, simulando uma interação, com o principal objetivo de mensurar o nível de cooperação de cada participante. Ambos adotaram como desenho de pesquisa modelo quase experimental e se apresentaram robustos por produzirem evidências suficientes para se acreditar na possibilidade de construção de jogos digitais, ainda que competitivos, mas que enfatizem e avaliem a cooperação.

Dessa forma, diante de um contexto social inflamado, que fomenta uma sociedade com práticas individualistas, que promove a necessidade de sobrevivência em um sistema 
econômico e cultural contemplado pela competição que propaga um discurso discriminatório (que reforça a desigualdade, fortalece o preconceito e a exclusão), fica evidente a necessidade de fortalecermos comportamentos e práticas que corroborem para um desenvolvimento social com mais empatia, respeito e colaboração.

Assim, os poucos resultados apresentados nesse estudo evidenciam a importância da criação e desenvolvimento de mais programas de intervenção para jogos digitais que se explica pela urgência de estratégias pedagógicas inovadoras no âmbito da educação, que desenvolvam competências e habilidades que valorizem a cooperação e a coletividade para melhorarmos a sociabilidade das próximas gerações nesse mundo digital. Além disso, faz-se necessário estimular pesquisadores e educadores envolvidos na área da educação, aprendizagem e dos serious games a investirem no processo de criação e desenvolvimento de jogos para desta forma termos mais recursos de aprendizagem cooperativa que motivem as crianças para o coletivo.

Por fim precisamos assumir a limitação deste estudo pelo fato de termos encontrados nas buscas somente dois estudos que contemplassem os critérios de inclusão, fator que evidencia a necessidade de investimentos nessa área. No entanto, tal carência clama por pesquisas mais aplicadas com o intuito de criação de novas estratégias, protocolos e produtos que se utilizem das novas tecnologias cada vez mais disponíveis em nossas escolas e instituições de educação.

\section{REFERÊNCIAS}

BRINCHER, S.; SILVA, F. Jogos digitais como ferramenta de ensino: reflexões iniciais. Outra Travessia, v. 1, n. 1, p. 42-69, 2012. Disponível em: https://periodicos.ufsc.br/index.php/Outra/article/view/2176-8552.2011nesp1p42. Acesso em: mar. 2019.

BROTTO, F. O. Jogos cooperativos: o jogo e o esporte como um exercicio de convivencia. Orientador: Roberto Rodrigues Paes. 1999. 197 f. Dissertação (Mestrado) - Universidade Estadual de Campinas, Faculdade de Educação Fisica, Campinas, SP. Disponível em: http://www.repositorio.unicamp.br/handle/REPOSIP/274877. Acesso em: mar. 2019.

GALVÃO, T. F.; PANSANI, T. de S. A.; HARRAD, D. Principais itens para relatar revisões sistemáticas e meta-análises: A recomendação PRISMA. Epidemiologia e Serviços de Saúde, v. 24, n. 2, p. 335-342, 2015. Disponível em:

http://scielo.iec.gov.br/pdf/ess/v24n2/v24n2a17.pdf. Acesso em: mar. 2019.

HUIZINGA, J. Homo ludens. 4a ed. São Paulo: Editora Perspectiva, 2000.

\section{JOANA BRIGGS INSTITUTE. Critical appraisal checklist for quase-esperimental}


studies (non-randomized experimental studies). 2017. Disponível em

http://joannabriggs.org/research/critical-appraisal-tools.html. Acesso em 03 mar 2019.

JOHNSON-GLENBERG, M. C.; HEKLER, E. B. Alien health game: an embodied exergame to instruct in nutrition and MyPlate. Games for Health Journal, v. 2, n. 6, p. 354-361, 2013.

KEIL, J. et al. The pizzagame: a virtual public goods game to assess cooperative behavior in children and adolescents. Behavior research methods, v. 49, n. 4, p. 1432-1443, 2017.

MATSUMOTO, L. E.; CAMPOS, L. M. L. Favorecendo a cooperação entre crianças: relato de uma experiência. Revista Simbio-Logias, v. 1, p. 200-213, 2008.

PIAGET, J. A formação do símbolo na criança, imitação, jogo, sonho, imagem e representação de jogo. São Paulo: Zahar, 1971.

POPPER, K. R. A lógica da pesquisa científica. Trad. Leônidas Hegenberg. São Paulo: Cultrix, 2. ed. 1974.

SERAPIÃO, J. de A. Educação Inclusiva: jogos para o ensino de conceitos. Editora Papirus, 2004.

SOUZA, M. T. C. de.; PETTY, A. L. Programa de intervenção com jogos: teoria e prática.

Rev. Cult. Ext., São Paulo, v. 18, p. 25-36, nov. 2017 DOI:

http://dx.doi.org/10.11606/issn.2316-9060.v18i0p25-36

VYGOTSKY, L. S. A formação Social da mente: o desenvolvimento dos processos

psicológicos superiores. Cole Michael et al., (Org.). São Paulo, Martins Fontes, 1994.

\section{Como referenciar este artigo}

DANIELLI, Françoise; FREITAS, Kamyla Thais Dias de; PEREIRA, Rubiane Guarino; CARDOSO, Fernando Luiz. Criação e desenvolvimento de jogos digitais cooperativos para crianças: uma revisão sistemática. Revista Ibero-Americana de Estudos em Educação, Araraquara, v. 15, n. 3, p. 1295-1308, jul./set. 2020. e-ISSN: 1982-5587. DOI: https://doi.org/10.21723/riaee.v15i3.13069

Submetido em: 28/10/2019

Revisões requeridas em: 19/11/2019

Aprovado em: 19/02/2020

Publicado em: 20/02/2020 